\title{
Portais de periódicos científicos, digitalização retrospectiva e sua repercussão
}

\author{
Angélica C. D. Miranda \\ Prof. no Departamento de Biblioteconomia e História - FURG \\ Doutoranda no Programa de Pós-graduação \\ em Engenharia e Gestão do Conhecimento - UFSC
}

Fundação Universidade Federal do Rio Grande Portal de Periódicos

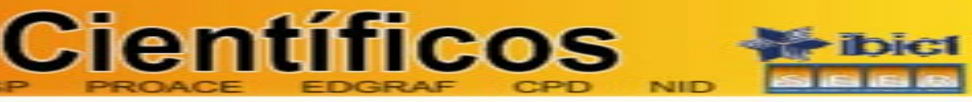




\section{Fundação Universidade Federal do Rio Grande - FURG}
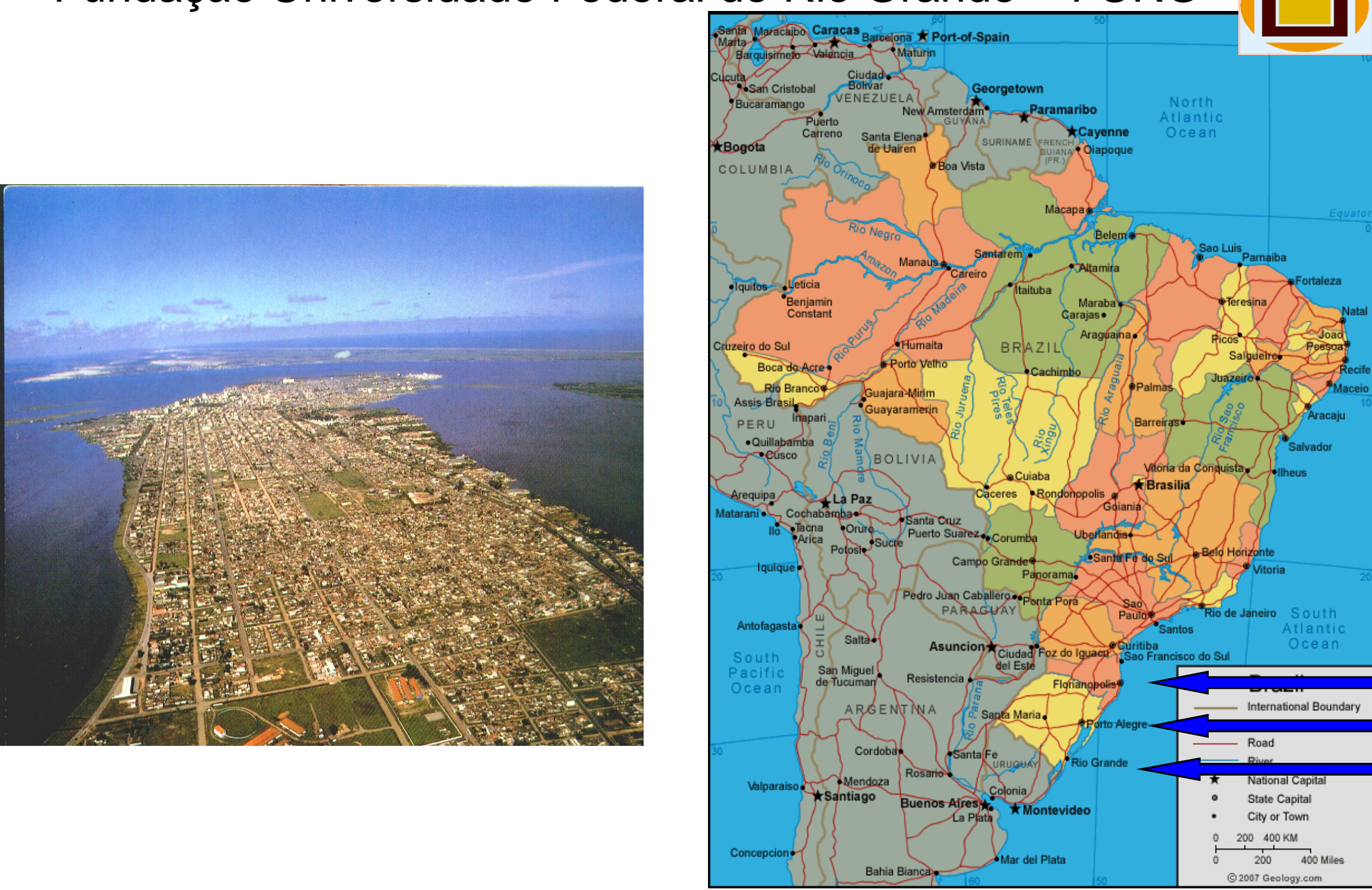

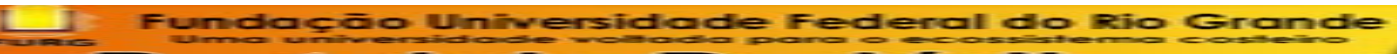
portal de Perí́ndicos 


\section{Objetivo}

Ampliar a visibilidade da produção intelectual da FURG.

\section{Histórico}

2005 - Versão OJS 1.x

BIBLOS - Revista do Departamento de Biblioteconomia e História

2006 - Versão OJS 2.1.1.0

BIBLOS - Revista do Departamento de Biblioteconomia e História

VETOR - Revista de Ciências Exatas e Engenharias

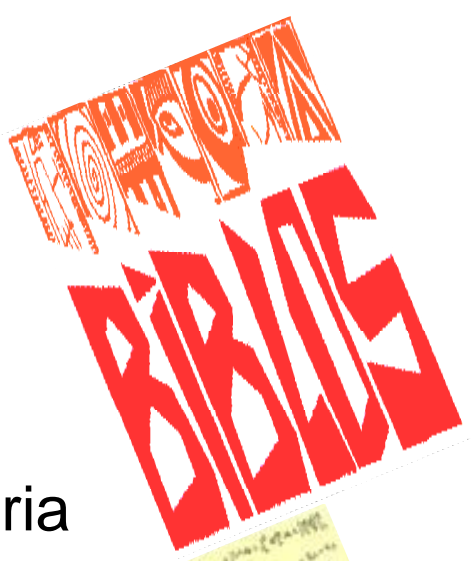

Portal ae P emíbdícos

diemtificos 
2007-

Pró-reitoria de Pesquisa e Pós-graduação

Pró-reitoria de Assuntos Comunitários e Estudantis

- Programa de apoio às publicações

- Aquisição do servidor

- Migração dos dados

- outros periódicos

2008 - Capacitação dos Editores - Curso

- Adequação das Revistas ao Portal 

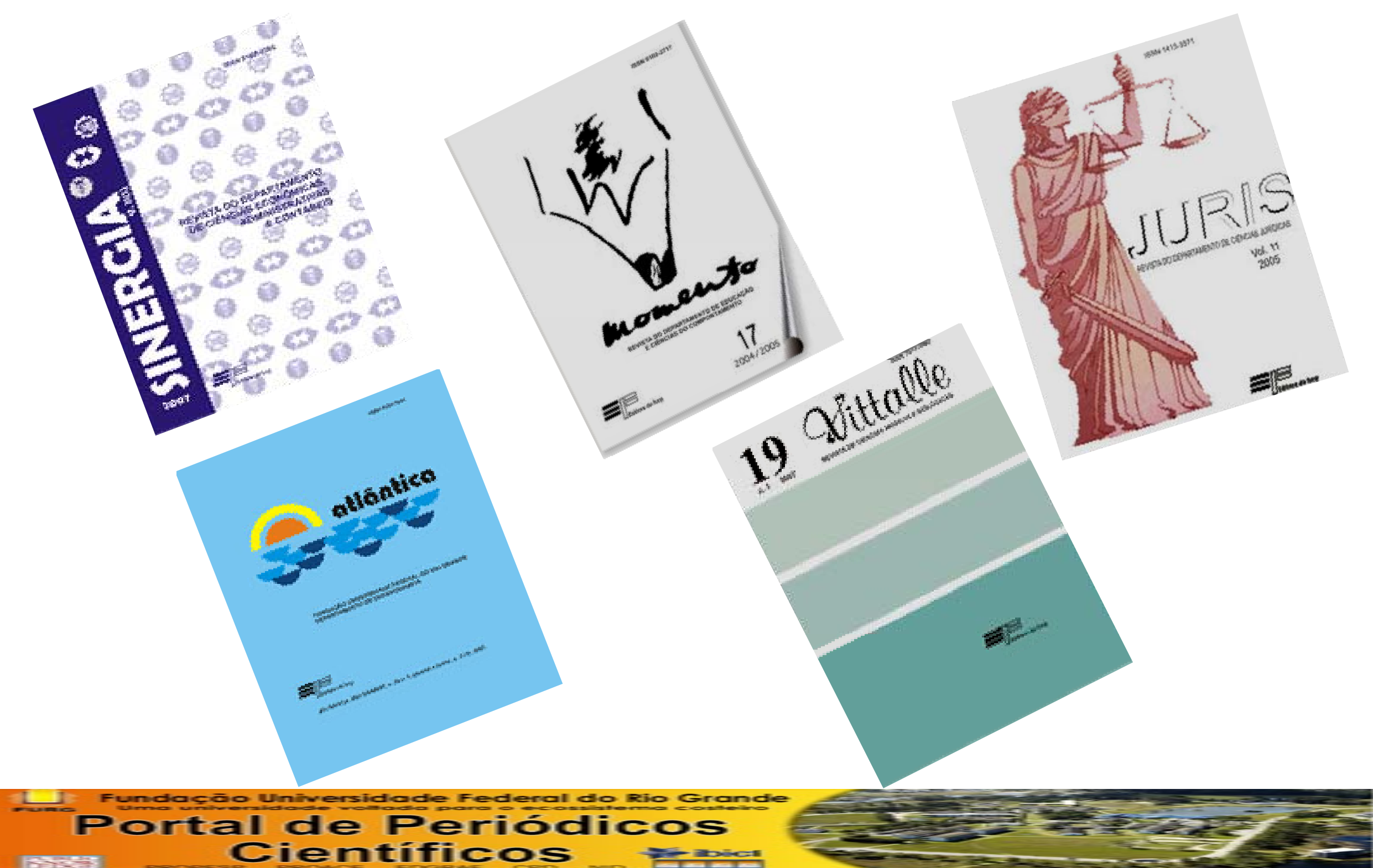


\section{Políticas}

\section{Sapacitação dos editores}

\section{sadronização}




\section{Cultura tecnológica local}

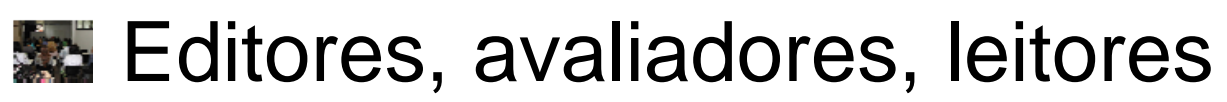

墱 Editora e Gráfica da FURG - EDIGRAF

龊 Instituição 


\section{Dificuldades}

\section{Vantagens}

1- Processo de conscientização

2- Disseminação do OJS

3- Digitalização retrospectiva requer fidedignidade

4- Metadados dos autores
1- Metodologia de trabalho (ambiente interativo online)

2- Parcerias institucionais

3- Integração da equipe

4- Ampliação da produção científica institucional

\section{Custo operacional:}

- 3 bolsistas do curso de Biblioteconomia da FURG (Bolsa FURG).

- 1 bolsista voluntário do curso Sistema para Internet da FAS (Programação Visual). 


\section{Resultados}

Sete revistas no Portal

国 Parcerias institucionais

图 Editores

Biblioteca

圆 Editora e Gráfica da FURG - EDIGRAF

圆 Administração

\section{Tendências}

W Conscientização dos atores envolvidos

5iveservação digital

점 Adesão das demais revistas

5ivulgação do Portal de Periódicos 


\section{PRÓ REITORIA DE PESQUISA E PÓS GRADUAÇÃO - PROPESP}

Pró-reitor Prof. Luiz Eduardo Maya Nery

\section{PRÓ REITORIA DE ASSUNTOS COMUNITÁRIOS E ESTUDANTIS - PROACE}

Pró-reitora Assistente Social Darlene Torrada Pereira

\section{Equipe operacional:}

Professora Angélica C. D. Miranda

\section{Acadêmicos:}

Jeane Lima ( $2^{\circ}$ ano - Bel. em Biblioteconomia - FURG)

Stephan Weska_(2 ano - Bel. em Biblioteconomia - FURG)

Helena Moraes ( $2^{\circ}$ ano - Bel. em Biblioteconomia - FURG)

Ademar Moraes ( $2^{\circ}$ ano - Sistemas para Internet - FAS)

Hospedagem e manutenção do sistema: Centro de Processamento de Dados - CPD

Apoio: Departamento de Biblioteconomia e História - DBH

Núcleo de Informação e Documentação - NID

Ligado a Editora e Gráfica da FURG - EDGRAF

Agradecimento aos ex-bolsistas do Projeto, em especial, Maritza Martins,

Simone Bandeira (2005) e Clériston Ribeiro (2006/07). 
$\square$ Fundação Universidade Federal do Rio Grande FURG Uma universidade voltada para o ecossistema costeiro

\section{Portal de Periódicos Científicos PROPESP

PUBLIC
KNOW

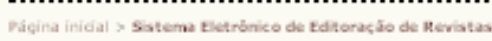

Sistema Eletrônico de Editoração de Revistas

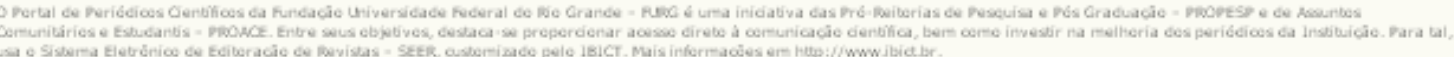

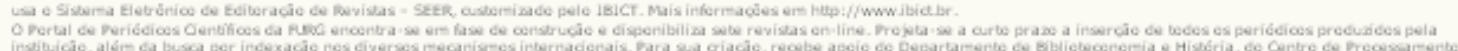

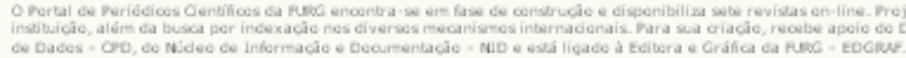

BIBLOS - Revista do Departamento de Biblioteconomia e História
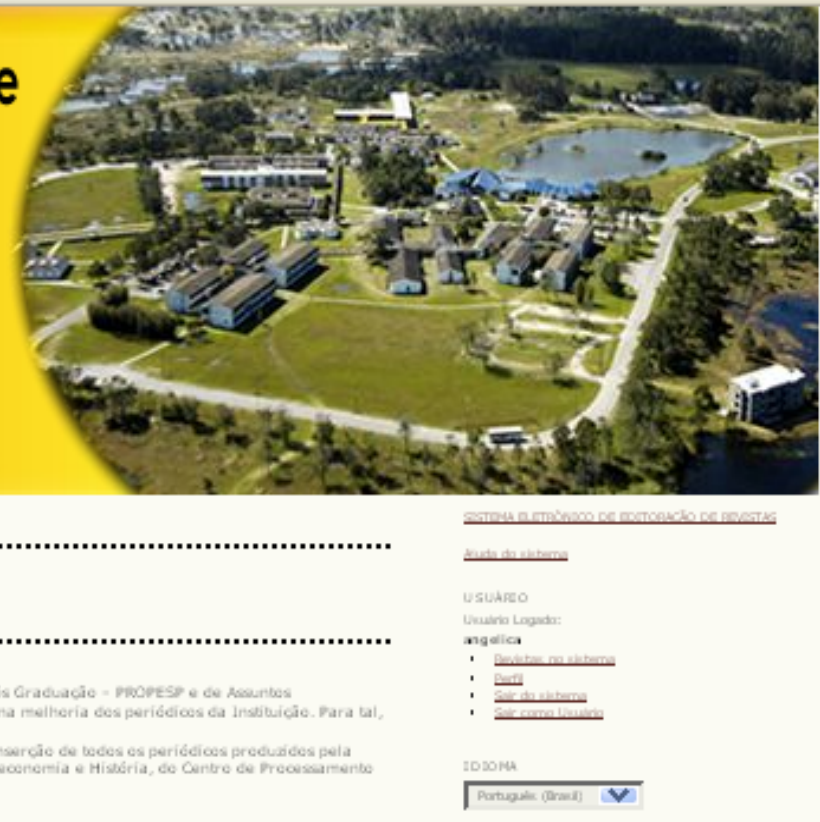

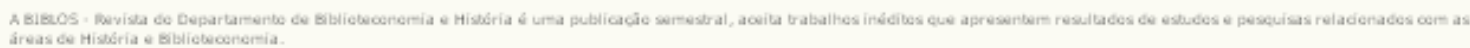

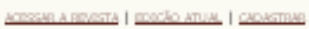

VETOR - Revista de Ciências Exatas e Engenharias

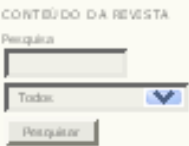

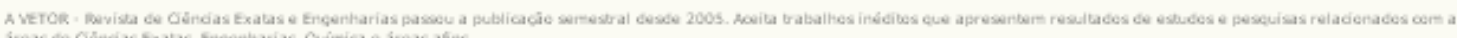

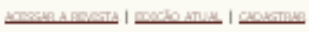

JURIS - Revista do Departamento de Ciências Jurídicas

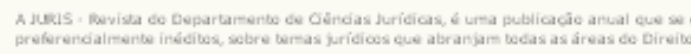

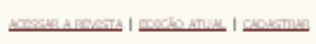

MOMENTO - Revista do Departamento de Educação e Ciências do Comportamento

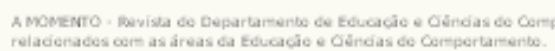

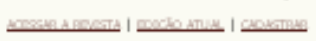

SINERGIA - Revista do Departamento de Ciências Econômicas, Administrativas e Contábeis

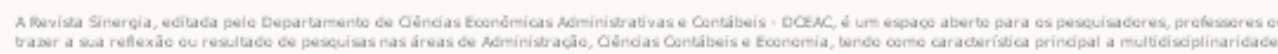

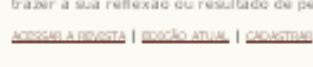

Atlântica (Rio Grande)

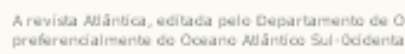

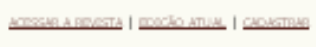

VITTALLE - Revista de Ciências Médicas e Biológicas 
Missão: Preparar profissionais.

Desafio: Conscientizar as administrações das Instituições.

\section{Obrigada!}

angelicacdm@gmail.com 